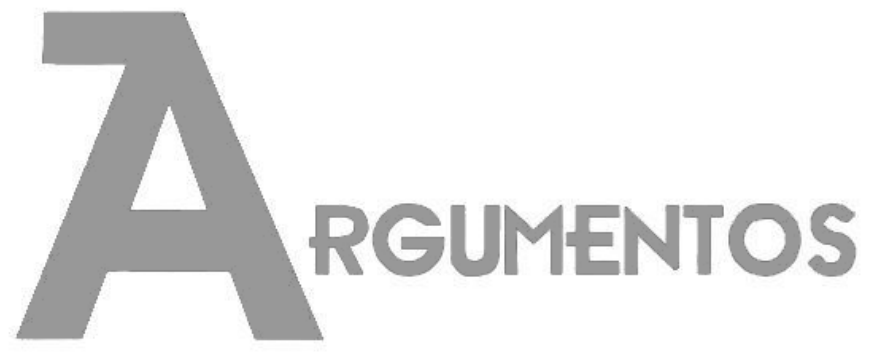

Vol. 16, n. 2, jul./dez. 2019 ISSN: 2527-2551 (online)

\title{
Breve estudo sobre o materialismo e a Teoria do Ator-Rede com foco em sua corrente novo materialista ${ }^{1}$
}

\author{
lan Coelho de Souza Almeida ${ }^{2}$
}

Recebido em: 01/11/2018

Aprovado em: 01/06/2019

\begin{abstract}
Resumo: $\mathrm{O}$ artigo tem o objetivo de analisar a vertente da Teoria do Ator-Rede que se aproxima do Novo Materialismo, traçando um breve histórico do material ismo, dando foco à modificação que a teoria marxista representou dentro do mesmo e a diferença para essa nova forma de materialismo. Se Marx se distancia de Hegel e Feuerbach ao dar centralidade à categoria trabalho, o Novo Materialismo, inspirado na obra Deleuze, tenta se distanciar tanto da modernidade quanto da pós-modernidade, partindo de uma consideração de nenhuma díade. Nessa Semiótica Material ista do ator-rede, a matéria deixa de representar al go inerte, à espera da ação humana, da ação de um ser dotado de vitalidade; de um ser racional sobre um irracional. Por fim, nos baseando na distinção entre ambosmaterialismos, apresentamos uma crítica à essa versão da ANT com base no materialismo histórico.
\end{abstract}

Palavras-chave: Materialismo; Novo Materialismo; Teoria do Ator-Rede; Marxismo.

\section{Breve estudio sobre el materialismo y la Teoría del Actor-Red con foco en su corriente nuevo materialista}

Resumen: El artículo tiene el objetivo de analizar la vertiente de la Teoría del Actor-Red que se aproxima al Nuevo Materialismo, trazando un breve histórico del materialismo, dando foco a la modificación que la teoría marxista representó dentro del mismo y la diferencia para esa nueva forma de materialismo. Si Marx se aleja de Hegel y Feuerbach al dar centralidad a la categoría de trabajo, el Nuevo Materialismo, inspirado en la obra Deleuze, intenta distanciarse tanto de la modernidad y de la posmodernidad, partiendo de una consideración de ninguna diade. En esta Semiótica Materialista del actor-red, la materia deja de representar algo inerte, a la espera de la acción humana, de la acción de un ser dotado de vitalidad; de un ser racional sobre un irracional. Por último, basándose en la distinción entre ambos materialismos, presentamos una crítica a esa versión de la ANT con base en el materialismo histórico.

\footnotetext{
${ }^{1} \mathrm{O}$ autor agradece os comentários em versões anteriores dos professores Carlos Eduardo Suprinyak e Leonardo Gomes de Deus, assim como de dois revisores anônimos.

2 Atualmente é professor substituto na área de Finanças do Instituto Federal do Norte de Minas Gerais, (IFNM), Brasil, e Doutorando em Economia pelo Cedeplar/Universidade Federal de Minas Gerais (UFMG), Brasil. E-mail: iancoelhobj@gmail.com. ORCID: https://orcid.org/0000-0002-1011-4517.
} 
Artigo | Breve estudo sobre o materialismo e a Teoria do Ator-Rede com foco em sua corrente novo materialista (ALMEIDA, lan Coelho de Souza)

Palabras-clave: Materialismo; Nuevo Materialismo; Teoría del Actor-Red; marxismo.

\title{
A brief study on materialism and the Actor-Network Theory focusing on it's new materialistic stream
}

\begin{abstract}
This paper aims at analyzing the stream in Actor-Network Theory close to New Materialism from the perspective of its materialistic roots, briefly, outlining the history of materialism, regarding the modifications represented by Marx's theory and the difference of the latter to New Materialism. Whilst Marx distances from Hegel and Feuerbach by giving centrality to labor, the New Materialism, inspired by Deleuze's work, attempts to depart from both modernity and post-modernity, assuming the inexistence of any dyad. In this actornetwork Materialist Semiotics, the matter no longer represents something inert waiting for human action, a being endowed with vitality; from a rational over an irrational being. Lastly, based on the distinction between these two materialisms, we present a critic of the ActorNetwork Theory based on historical materialism.
\end{abstract}

Keywords: Materialism; New Materialism; Actor-Network Theory; Marxism.

\section{Introdução}

Ao mesmo tempo que a Teoria do Ator-Rede (ANT, em inglês) vai ganhando espaço em cada vez mais campos de pesquisas (como estudos feministas, estudos de ciência e tecnologia, estudos culturais e etc.), vai também sendo cada vez mais foco de análise crítica de diversos pesquisadores. Tentativas de compreender ANT, e muitas vezes encaixa-la em linhas já existentes, como o pós-modernismo, o construtivismo e etc., se multiplicam. Dentre as várias abordagens que procuram se posicionar frente à ANT estão as teorias marxistas, que inspira nossa perspectiva de análise.

Enquanto esse trabalho tem a intenção de compreender as contribuições da ANT, o faz por um caminho bem específico, através de sua versão mais próxima ao novo materialismo e o modo como essa se distancia dos demais tipos de materialismo. Essa linha de ação nos permitirá três objetivos: entender o que se propõe a ANT a partir de sua relação com o materialismo, analisar em quais pontos ela se diferencia e se aproxima com teorias às quais é corriqueiramente comparada, e apontar caminhos para críticas mais frutíferas partindo de uma consideração histórico-materialista.

A intenção de trazer a crítica marxista à ANT encontra dificuldades na própria definição de ANT. Como apontado em diversos trabalhos da área, e algo que será enfatizado ao longo deste artigo, ANT não é uma teoria do modo comum que entendemos, mas algo ligado à própria prática da análise. Esse é o principal motivo de termos selecionado uma de suas correntes mais comuns, para conseguir apresenta $\mathrm{rm}$ contraponto do materialismo-histórico. Por sua vez, justifica-se a escolha do 
Artigo | Breve estudo sobre o materialismo e a Teoria do Ator-Rede com foco em sua corrente novo materialista (ALMEIDA, lan Coelho de Souza)

materialismo como ponto central de análise por esse ser a base do pensamento marxista, muitas vezes contraposto aos avanços da ANT.

Para cumprir tal objetivo, dividimos nosso trabalho em outras quatro sessões. Na primeira traçamos o materialismo da teoria da história de Marx, dando foco a como ele se diferencia diametralmente dos materialistas antecessores, muita influenciado por uma visão que começou a ser formada, mas não consolidada, por Feuerbach. Em seguida mostramos como a proposta do "Novo Materialismo", desenvolvido na segunda metade do século XX, difere daquele utilizado pelos marxistas.

$\mathrm{Na}$ quarta sessão, introduzimos algumas versões da ANT e, posteriormente, identificamos os desdobramentos do materialismo presente no Materialismo Semiótico, assim como algumas críticas marxistas à essa abordagem. Apresentamos, também, nosso entendimento de como elas podem ser enriquecidas a partir da incorporação das discussões apresentadas nesse trabalho. Por fim, concluímos.

\section{Breve histórico do materialismo até Marx}

Traçando as raízes do materialismo, como fez Lange (1925 [1865]), podemos partir do desenvolvimento do atomismo por Demócrito, que ao fixar a essência da matéria como aquilo indispensável para a existência no tempo e no espaço, tornou-a, assim, o substrato de qualquer fenômeno, se afastando do dualismo e da personificação que imperavam até então. Esse avanço teve grande importância, principalmente para as ciências naturais, da qual se tornou base. "[...] mesmo a insuficiência de toda teoria mecânica no mundo poderia aparecer apenas dessa maneira, por que essa era a única maneira através da qual uma explicação poderia ser alcançada" (Ibidem, v.1, p.14 tradução própria).

A partir do atomismo de Demócrito, passando pela doutrina dos vórtices de Descartes, e pela teoria newtoniana, temos o período caracterizado pelo domínio na Física do que Bertrand (1925) denomina "determinismo físico" ${ }^{3}$. Apesar de, como aponta o autor, o materialismo não ter sido amplamente difundido entre os estudiosos

\footnotetext{
3 "[...] a belief that what happens in the world dealt with by physics happens in the world dealt happens according to laws such that, if we knew the rolestate of the physical world during a finite time, however short, we could theoretically infer its state at any earlier or later time" (BERTRAND, 1925, p. IX)
} 
Artigo | Breve estudo sobre o materialismo e a Teoria do Ator-Rede com foco em sua corrente novo materialista (ALMEIDA, lan Coelho de Souza)

de seu tempo, e do de Lange [o que voltará a ser verdade a partir da década de 1970, como apontam Coole e Frost (2010)], aqueles que o perseguem o fazem como forma de aproximar sua prática científica à física (na realidade, à essa ideia da matéria que foi dominante na física até o surgimento da teoria da relatividade).

No que tange à Filosofia, é com Pierre Gassendi e Thomas Hobbes que o materialismo ganha mais clareza. Contemporâneos, e muito próximos pessoalmente, principalmente em suas críticas a Descartes (Sorell, 2005), os dois autores podem ter uma distinção traçada em relação aos seus materialismos a partir do grau que esse alcança em sua teoria. Enquanto Gassendi dividia a alma em corpórea e vegetativa, onde a segunda não necessariamente obedecia a primeira, Hobbes negava a existência de uma parte incorpórea da alma. "[A] teoria do conhecimento [de Hobbes] não recorria a nenhuma capacidade psicológica ou entidades espirituais puras" (Ibidem, p.220 tradução própria).

Além da França e Inglaterra, países de Gassendi e Hobbes respectivamente, ainda durante a passagem do século XVII e XVIII o materialismo pode ser observado também na Alemanha, onde encontra a oposição metafísica de Gottfried Leibniz (Lange, 1925 [1865], v.2). Enquanto o materialismo se debatia com questões como a localidade das sensações e a consciência ${ }^{4}$, Leibniz desenvolvia a teoria da Monadologia. Apesar de, como no atomismo, partir de um princípio onde há uma substância elementar, a mónada, ao contrário do átomo, é imaterial e atemporal"5: "Não se pode supor que a combinação de tamanhos, formas e movimentos possa produzir algo que pensa, e também sente, em uma massa onde não havia nada do tipo anteriormente" (Leibniz, 1981 apud Wilson, 1997, p.345 - tradução própria). Ao invés da sensação ser produzida pela interação das substâncias essenciais, fisicamente, cada substância desenvolve as próprias sensações ${ }^{6}$, tendo sua interação sistêmica estabelecida de modo

\footnotetext{
4 "Do they consist in the combination of atoms? Then they exist in abstraction, and are, objectively speaking, nowhere. Are they in motion? That would be the same thing. We only regard the moving atoms itself as the seat of sensation. How, then, does sensation result in consciousness? Where is this consciousness?" (Lange, 1925 [1865], v.2, p.127)

5 "For a seventeenth century philosopher, the supplementation of physics with hyperphysics is not unusual and needs no special explanation; hyperphysics fills in explanatory gaps in mechanical philosophies and simultaneously deflects charges of impiety and atheism." (Wilson, 1997, p.339). Como coloca Lange (1925), todos esses desenvolvimentos da metafísica acabavam por se misturar de alguma maneira com a fé religiosa.

6 "é uma mónada se des envolvendo de acordo com suas leis internas" (Lange, 1925, v.2, p.128 - tradução própria)
} 
Artigo | Breve estudo sobre o materialismo e a Teoria do Ator-Rede com foco em sua corrente novo materialista (ALMEIDA, lan Coelho de Souza)

completamente harmônico antes que houvesse tempo (a ideia de Deus), sendo a aparição da sensação, memória e pensamento dependentes do nível que a mónada se encontra dentre aquelas do mundo orgânico (Ibidem).

Seguindo na Alemanha, muito em oposição às influências do iluminismo francês que tentava ganhar espaço no país, está um dos mais destacados filósofos dos séculos XVIII e XIX, Georg W. Friedrich Hegel, e seu idealismo. Era em oposição à Hegel que os materialistas da época desenvolviam suas teses, sendo um dos mais notáveis Ludwig Feuerbach, além de outros que incorporavam ideias Darwinianas, como Karl Vogt, Jacob Moleschott e Ludwig Büchner (Gregory, 1977). Os últimos foram materialistas muito conhecidos naquele país durante segunda metade do século XIX, tendo todos sofrido perseguições na vida acadêmica por seus trabalhos que negavam não só existência de um força vital, mas também da alma (Ibidem, p.209). No entanto, esses ainda obedeciam ao que chamamos de materialismo metafísico, ou científico [como coloca Gregory (1997)], dividindo pressupostos com os metafísicos anteriormente citados, em oposição ao materialismo dialético ${ }^{7}$ de Marx.

Vogt, Moleschott, e Büchner não entendiam por materialismo aquilo que Marx e Engels entendiam. [...] os materialistas científicos se baseavam na afirmação reducionista de que 'quaisquer propriedades ou formas de comportamento objetos particulares exibem são, em última instância, explicáveis através de leis gerais que se aplicam igualmente a todas as manifestações da matéria." (GREGORY, 1977, p.216, tradução própria)

O que acontece, então, é que essa linha de materialismo utilizava uma aproximação ao materialismo da física para justificar seus pressupostos metafísicos ${ }^{8}$ de que a realidade é baseada no material. Isso serve como oposição, por exemplo, à também já mencionada metafísica de Leibniz, que partia do imaterial, e divino, para explicar a realidade. É a dialética Hegeliana que apresentará uma oposição real à metafísica, no entanto, tendo como base o imaterial. O trânsito do "universal abstrato",

\footnotetext{
7 Marx não nomeava seu materialismo de histórico dialético, apenas de histórico. Essa terminologia foi apresentada, na realidade, por Plekhanov.

8 A metafísica pode ser encontrada tanto dentro idealismo quanto do materialismo. "Os sistemas metafísicos foram sempre a obra de um filós ofo, que acreditava sempre estar trazendo a chave pa ra todos os enigmas, de modo que, segundo ele, a história do homem e do pensamento desembocavam nele e chegavam com ele a seu ponto final" (Lefebvre, 1995, p.52, ênfase no original)
} 
Artigo | Breve estudo sobre o materialismo e a Teoria do Ator-Rede com foco em sua corrente novo materialista (ALMEIDA, lan Coelho de Souza)

que passará pelo específico e chegará ao "universal singular", tudo isso dentro do pensamento, nas ideias, através do processo de negação da negação, onde a negação da própria Ideia gera a Natureza, sua antítese. (Sampaio; Frederico, 2009).

Para Marx, posição em relação ao materialismo que desejamos alcançar, é Feuerbach o único entre os seus contemporâneos a ter uma atitude crítica frente à dialética idealista hegeliana (Marx, 2010, p.117). Apesar disso, e de ter sofrido grande influência do mesmo, Marx faz profundas críticas e se separada definitivamente de seu pensamento: "Feuerbach parou a meio caminho: embaixo era materialista, em cima era idealista" (Engels, 2006, p. 121). Isso acontece quando, para Marx, Feuerbach acaba por cair novamente no idealismo, dado que seu homem social abstrai-se tanto das relações sociais, quanto da história. (Redyson, 2011, p.11).

Feuerbach retoma o iluminismo negando a dialética hegeliana. E faz isso ao tentar fugir do idealismo de Hegel, recolocando o "ser" enquanto sujeito e o Espírito como algo dependente da natureza. "Os seres naturais, como se pode ver, readquirem não só a sólida base de si mesmos, como também passam a ser o fundamento único, incondicionado e permanente do Espírito" (Sampaio; Frederico, 2009, p.51).

No entanto, Feuerbach tem papel fundamental na fundação do "verdadeiro materialismo" exatamente por tomar "a relação do homem com o homem, como princípio fundamental da teoria" (Marx, 2010, p.118). Ainda assim, algumas das objeções de Marx à sua teoria podem ser encontradas sintetizadas na obra Teses ad Feuerbach. A primeira tese, por exemplo, aponta como o materialismo desse autor, apesar de reconhecer os objetos sensíveis, materiais, o faz apenas de forma puramente teórica, e não como atividade humana, por não reconhecer a atividade humana como objetiva (Marx, 2006, p.117) ${ }^{9}$. O “materialismo antropológico" de Feuerbach, então, apesar de identificar a importância da condição material para a consciência humana, não avançou no papel que o trabalho teria na satisfação das mesmas (Wartofsky, 1977,

\footnotetext{
9 "[...] a part from the fact that he only conceives him as an 'object of the senses', not as 'sensuous activity', because he still remains in the realm of theory and conceives of men not in their given social connection, not under their existing conditions of life, which have made them what they are, he never arrives at the actually existing, active men, but stops at the abstraction 'man' [...]Thus he never manages to conceive the sensuous world as the total living sensuous activity of the individuals composing it." (Marx; Engels, 1998, p.46-47)
} 
Artigo | Breve estudo sobre o materialismo e a Teoria do Ator-Rede com foco em sua corrente novo materialista (ALMEIDA, lan Coelho de Souza)

p. XVII). Também por essa lacuna, seu trabalho serviu como inspiração para o materialismo de autores como Vogt, Moleschott e Büchner.

O materialismo de Marx, seguindo aquilo iniciado mas não concluído por Feuerbach, irá se distanciar desses demais que se inspiram no atomismo, no mecanicismo, que estavam inseridos dentro da metafísica (mesmo tendo esse materialismo vulgar, como explicita Sidney Hook (1928), se distanciado do idealismo ao reconhecer a autossuficiência material do mundo). É partindo da dialética hegeliana (e negando seu idealismo), em contraponto à lógica metafísica Aristotélica, que o materialismo dialético de distinguirá do seu antecessor da seguinte forma, exposta por Hook:

(a) A totalidade dos fenômenos não pode ser reduzida a questões meramente físicas (massa, comprimentoe tempo). Para Marx a matéria não exclui outras formas de energia. "the psychology of thought and emotion is not necessarily the chemistry of brain tissue and the chemistry of the brain is not the mechanics of bodies in motion" (Ibidem, p.121)

(b) Existe a possibilidade de evolução das formas de consciência, que ocorre não só de forma direta, mas também histórica (Ibidem). Isso tem implicação direta do processo dialético, da negação da negação. O conhecimento se torna historicamente cumulativo, e evolui da contradição surgidas ao longo da história.

(c) Por ser a-histórico, o materialismo metafísico não era capaz explicar a história da sociedade humana (Ibidem, p.122), caráter crucial no materialismo histórico de Marx, onde a história da sociedade é a história da luta de classes.

Sendo assim, a crítica à dialética idealista Hegeliana, iniciada por Feuerbach e estendida a seu estágio mais desenvolvido por Marx, não só se afasta de explicações puramente da consciência, como também modifica o que se entende por materialismo. É a utilização da práxis como mediação ativa dentro da dialética (Sampaio; Frederico, 2009, p. 57). Marx reabilita a dialética, mas nega o idealismo Hegeliano ao não posiciona-la "no interior de um pensamento abstrato que se autodesenvolve [...] mas simna vida social empírica dos homens, como história real e necessária" (Ibidem, p.60). Sendo assim é o trabalho enquanto mediação no processo dialético que represente o avanço do materialismo de Marx. 
Artigo | Breve estudo sobre o materialismo e a Teoria do Ator-Rede com foco em sua corrente novo materialista (ALMEIDA, lan Coelho de Souza)

\section{Do materialismo histórico-dialético ao novo materialismo}

Tendo avançado criticamente sobre os trabalhos de Feuerbach e Hegel, Marx traz para si uma modificação do determinismo da história do último. Para Hegel o avanço da história se dá com o desenvolvimento da consciência do espírito do mundo (que pode ser entendido como o espírito de pessoas de diferentes épocas). Aqui o indivíduo não importa, mesmo se diferenciando dos demais, pois o relevante é apenas o espírito do povo, Volksgeist, do qual o indivíduo é indistinguível (Therborn, 1976, p.340). É o desenvolvimento desse espírito que determinará a sociedade civil, tendo a história do mundo iniciado para satisfazê-lo, e se desenvolve em busca de sua consciência (Ibidem, p.341) ${ }^{10}$.

Marx modifica a determinação social hegeliana a partir de um novo entendimento do materialismo, não mais aquele apenas em oposição ao clérigo, mas um onde a realidade e a necessidade material direcionam a consciência e o trabalho humano ${ }^{11}$. O trabalho é o único o meio de saciedade dessa necessidade e ponto inicial da história, que se desenvolverá a partir das contradições geradas dentro das relações de produção das quais o homem será parte, das lutas de classes.

É no prefácio da Contribuição da Crítica à Economia Política que muitos marxistas buscam uma compreensão concisa do método de Marx (e.g. Therborn, 1976, p. 353; Burawoy, 1990; Bersntein, 1981).

\footnotetext{
"A conclusão geral a que cheguei e que, uma vez adquirida, serviu como fio condutor dos meus estudos, pode formular-se resumidamente assim: na produção social da sua existência, os homens estabelecem relações de produção que correspondem a um determinado grau de desenvolvimento das forças produtivas materiais. 0 conjunto destas relações de produção consti tui a estrutura econômica da sociedade, a base concreta sobre a qual se el eva a superestrutura jurídica e política e à qual correspondem determinadas formas de consciência social. O modo de produção da via material condiciona o desenvolvimento da vida social. Não é a consciência dos homens que determina o seu ser; é o seu ser social que, inversamente, determina sua consciência" (Marx, [1859] 2011, p.5, grifo nosso)
}

\footnotetext{
10 É daí, segundo Therborn, que vêm a crítica de Marxistas, como Althusser, de que a história de Hegel é um "processo sem sujeito".

11 Apesar de tratarmos aqui da centralidade do trabalho para Marx, não exaurimos o assunto, principalmente por não tratarmos diretamente da atividade sensível, através da qual o homem produz o mundo. A respeito disso, ver, por exemplo, Gontigo (2008) e Oliveira (2010).
} 
Artigo | Breve estudo sobre o materialismo e a Teoria do Ator-Rede com foco em sua corrente novo materialista (ALMEIDA, lan Coelho de Souza)

O ser social, aquilo que para Marx determina a consciência, é fundado no trabalho ${ }^{12}$, nas relações de produção, as quais se relacionam com as forças produtivas formando a base material da sociedade. Essa base (ou estrutura) material constitui o modo de produção, que avança (do asiático, para o antigo, para o feudal, para o burguês), como resume Therborn (1976, p.361), não independentemente, mas modificando diretamente a vida social, a consciência. As contradições dentro da base, que impedem a continuidade do avanço material, se tornam conscientes para os homens, que as levam à última consequência. Ou seja, a luta de classes, na qual pode ser resumida a história, é alcançada pela tomada de consciência em relação às contradições entre as forças produtivas e as relações de produção.

Apesar de muito concisa, essa explicação do que é o materialismo históricodialético nos serve para apresentar o que significa o materialismo para Marx, e como isso difere do entendimento anterior. A partir disso, diversos teóricos marxistas o aprofundam e modificam de diversas maneiras, sendo do Leste (Maoístas, Stalinistas, Trotskistas e etc.) ou do Oeste (Althusserianos, Gramscianos, Frankfurtianos e etc.) ${ }^{13}$, que no entanto não são foco de nosso estudo. Dentre esses, aquele que está mais inserido nos debates que estudaremos a seguiré Althusser, como apontam Coole e Frost (2010) e Edwards (2010). No intuito de compreender a semiótica materialista da Teoria do Ator-Rede, o nosso foco será o "Novo Materialismo" (termo cunhado por Manuel DeLanda e Rosi Braidotti), que surge na segunda metade do século XX.

A importância de Althusser aqui vêm de sua relevância para o estruturalismo, forte expressão da dualidade modernista, que, assim como seus críticos pósestruturalistas e pós-modernos, vão constituir aquilo que o Novo Materialismo tenta evitar, tendo como uma de suas principais influências Gilles Deleuze (Dolphijn; van der Tuin, 2011). Esse Novo Materialismo surge em oposição às teorias humanistas e transcendentais, atacando suas bases dualistas, e também o pensamento dialético (van der Tuin; Dolphijn, 2010), de modo a evitar tanto o modernismo quanto o pós-

\footnotetext{
12 Ver Silveira Júnior (2013) e Vaisman (2010).

13 Sobre diferentes formulações marxistas, ver Therborn (2008).
} 
Artigo | Breve estudo sobre o materialismo e a Teoria do Ator-Rede com foco em sua corrente novo materialista (ALMEIDA, lan Coelho de Souza)

modernismo ${ }^{14}$ e se destacando enquanto uma das quatro versões do materialismo existentes contemporaneamente ${ }^{15}$.

Essa é uma abordagem no pensar sobre a matéria onde ela não é mais vista como algo inerte sujeito a forças externas, tampouco pode ser entendida meramente como seus próprios processos químicos, mas também como dotada de vitalidade, força, relacionalidade e etc., o que complexifica o que entendemos sobre causalidade (Coole; Frost, 2010). Não mais os seres humanos são tidos como os possuidores das habilidades cognitivas e intencionalidades para dominar aquilo que é material, a natureza, através do trabalho, por exemplo. Assim, a proposta dos autores dessa corrente se distancia da questão elaborada por Marx, onde a interações do homem com a matéria, sua necessidade e sua modificação, eram o início da história, e passam a compreender a matéria como algo que realmente não é, mas está (Ibidem, p.10), onde a aparente constância da matéria é apenas algo em um período de tempo. Dessa forma, ao modificar sua constância em uma nova constância, seja por meio de novas relações ou outra questão, a matéria deixa de ser objeto de ação e passa a ser agente. Se antes, no materialismo histórico, a matéria era objeto para ação humana através da interação entre relações de produção e forças produtivas (que seria assimilada em sua consciência), isso não ocorre mais, não há real divisão entre aquilo que é consciente e aquilo que não o é.

No caminho em busca de um novo materialismo, que não seja nem determinista, tampouco desemboque no idealismo, na questão da alma, Bennett (2010) apresenta um estudo que pode ser entendido como um dos primeiros passos em direção ao Novo Materialismo, o Entelechy, de Hans Driesch. Os escritos do filósofo e biólogo alemão do começo do século XX e partem do que se pode nomear como vitalismo crítico, sendo essa uma oposição a uma versão mais ingênua onde a força vital que separaria a vida da simples matéria seria a alma (isso se tornará mais claro à medida que apresentarmos a visão de Driesch) ${ }^{16}$.

\footnotetext{
14 Sobre a negação do pensamento dialético, ver Serres e Latour (1995).

15 As outras são, segundo Žižek (2014, p.5), a) um materialismo vulgar ligada ao neo-Darwinismo, b) uma vertente ateia muito focada na denúncia da religião e c) um materialismo discursivo, ligado a Foucault. 16 Bennett (2010 p.58-59) resume a posição do vitalismo ingênuo nos seguintes pontos: (a) A vida é radicalmente diferente da matéria; (b) A vida Humana é radicalmente diferente das demais vidas; (c) $A$ singularidade da vida humana expressa uma intenção divina; (d) A vida é uma ordem divinamente criada e essa ordem tem a forma de uma hierarquia fixa.
} 
Artigo | Breve estudo sobre o materialismo e a Teoria do Ator-Rede com foco em sua corrente novo materialista (ALMEIDA, lan Coelho de Souza)

O Entelechy é aquilo que dá multiplicidade aos organismos. Partindo da impossibilidade da matéria conseguir explicar de modo mecânico a vida e sem negar que o Entelechy seja mecânico, acabar o tornando algo psíquico. O Entelechy é apenas algo não-mecânico (Ibidem, p.51). É a "substância", se assim podemos chama-lo, que dá vida à matéria. Enquanto a matéria inorgânica pode apenas se modificar (aumentar ou diminuir de massa, por exemplo), aquela que possui vida pode se transformar (com especial espaço para a capacidade de substituir ou reparar suas partes com a manutenção da função). Outra forma que Driesch advoga a existência do Entelechyé a impossibilidade da matéria por si só, quando da criação de um novo organismo (o biólogo faz experimentos de embriologia), determinar a função a ser dada a cada nova célula e à união das mesmas. É a "substância" que têm esse "poder diretor" de escolher entre as milhares de possibilidades para esse novo organismo emergente (Ibidem, p.52) ${ }^{17}$.

O ponto de Bennett em trazer o Entelechy de Driesch para a discussão é contabiliza-lo como uma agência (agency) naturalista, enquanto força que opera no mundo, não espacializada ou calculável, algo que não seria oposto ao Novo Materialismo (NM). Se o antigo materialismo, o mesmo que Marx critica, determinista, onde tudo ocorria de forma mecânica, sujeito apenas aos próprios processos químicos, o novo absorve essa "substância" que nega que a vida seja entendida enquanto força divina ou pura mecânica. De certa forma isso se aproxima com a definição máquina abstrata $^{18}$ (discutida por Manuel DeLanda e apresentada por van der Tuin e Dolphijn (2010)), que abrange processos dentro de agrupamentos tanto sociológicos, quanto biológicos e geológicos, e não possuem forma ou substância.

Apesar de o trabalho de Driesch ser um afastamento importante do mecanicismo materialista, ao mesmo tempo que é do idealismo, ele fica longe de contemplar aquilo que, mesmo com as possíveis divergências sobre o que realmente seja o Novo Materialismo e com a heterogeneidade das teorias que compõe esse

\footnotetext{
17 "Entelechy, that self-directing activeness apparent in some bodies, is what distinguishes a crystal from an embryo, a parking lot from a lawn, me from my corpse.” (Bennet, 2010, p. 53, grifo no original).

18 Esse é um conceito originário de Deleuze e Guattari 1987 [1980].
} 
Artigo | Breve estudo sobre o materialismo e a Teoria do Ator-Rede com foco em sua corrente novo materialista (ALMEIDA, lan Coelho de Souza)

conjunto, serve de base ao NM: a negação a todo dualismo, o que inclui a oposição entre aquilo que é vivo e aquilo que é inerte, ponto de atuação do Entelechy. ${ }^{19}$

Apesar da importância da negação de todo e qualquer dualismo, o nosso objetivo é compreender como o entendimento de matéria é ressignificado dentro dessa discussão, como o inerte passa a ter possibilidades de agenciamento. Para abandonar essa visão da matéria sem propósito ou fim, sujeita apenas a leis de causa e efeito, Coole (2010) recorrerá à ideia de folded matter. Aqui há uma espécie de reciprocidade na matéria, como se o encontro de duas matérias fosse a união de dois planos constituindo um espaço bidimensional. Sendo assim, a interação de tudo aquilo constituído de matéria, que anteriormente poderia ser separado dentro do dualismo homem/natureza, é permeado de relacionalidade e reciprocidade. Nesse ponto é que a capacidade de agenciamento se torna algo desligado da superioridade do ser humano, ser racional, possuidor de força vital (como no caso de Driesch), sobre a natureza, mas advindo de um subproduto dessa intepretação de interação como dobras: reflexibilidade, comunicação criativa e transformação (Ibidem, p.113). Isso garante uma não diferença entre o orgânico e o inorgânico.

Enquanto Marx e Engels, partindo do trabalho de Feuerbach, foram responsáveis por distanciar o materialismo da pura mecânica, entendendo a relação entre homem e natureza a partir de sua interação através do trabalho, esse Novo Materialismo, que aqui focamos em sua relação com a Teoria do Ator-Rede, vêm negar a própria existência da distinção entre homem e natureza, colocando-os como mera matéria que interage e simultaneamente têm papel de agente. Abdica-se tanto do humanismo quanto de qualquer outra dualidade, seja moderna ou pós-moderna. "Subjetividade, corporeidade, não é mais uma propriedade dos humanos, dos indivíduos, dos sujeitos intencionais, do que ser uma realidade exterior é uma propriedade da natureza." (Latour, 2010, p. 23).

\footnotetext{
19 Exemplos mais finalizados e contemporâneos de um NM seria o Novo Feminismo Materialista, que aponta a teoria de Simone de Beauvoir como limitadora ao pertencer ao dualismo sexo versus gênero, e propõe um modo de pensar que se distancie da relação homem/mulher e masculinidade/feminilidade se aproximando de uma "unívoca' diferença sexual que permite a diferença sexual diferenciar" (Dolphijn; van der Tuin, 2011, p. 387, tradução própria). Uma das principais alegações para isso é que existiria um paradoxo entre a demanda política pela eliminação das diferenças de gênero com o pressuposto de diferenciação do qual o feminismo parte para realizar essa demanda. Em relação a isso, ver Scott (1996). Para uma solução para essa contradição dentro das linhas do NM, ver Colebrook (2004).
} 
Artigo | Breve estudo sobre o materialismo e a Teoria do Ator-Rede com foco em sua corrente novo materialista (ALMEIDA, lan Coelho de Souza)

A ANT aqui apresentada é entendia a partir da ideia de semiótica materialista, a ser explicitada na próxima seção. A semiótica materialista, assim como outras perspectivas, está ligada a essa "virada ontológica" do Novo Materialismo, principalmente no trabalho de Guilles Deleuze, como mostra Loon (2019).

\section{A semiótica materialista na Teoria do Ator-Rede e algumas tentativas de relaciona-la com o marxismo}

A década de 1980 viu uma grande ruptura nos estudos da ciência, com o surgimento de diversos campos de estudo para além dos tradicionais (Sociologia Clássica, Etnografia e Etnometodologia), como a Epistemologia Feminista, o Interacionismo Simbólico, a Teoria do Ator-Rede, Semiótica, a Análise do Discurso, experimentação com "novas formas literárias" e a celebração da reflexividade (Pleasants, 1993). Como coloca Elder-Vass (2015), a ANT é uma teoria social que se tornou dominante nos área dos Estudos da Ciência e da Tecnologia e foi ganhando espaço nas demais disciplinas, como a sociologia, ao mesmo tempo que se aproximava de outras tendências e correntes da teoria social, como o pós-humanismo, teoria da complexidade e o novo materialismo. A questão principal da ANT é descentralizar a agência, entender as relações e interconexões "onde nada existe antes performance ou atuação" (FENWICK; EDWARDS, 2011). Essas ações unidas são aquilo que produz as redes, que por sua vez são responsáveis por comportamentos, inovações, opressões e demais fenômenos sociais. Como realizar esse processo é o que diferencia os entendimentos da ANT.

Os primeiros escritos da ANT são de Michel Callon na década de 1980, algo ligado a sua ideia de uma "sociologia da tradução". O autor mostrou como engenheiros que buscavam criar redes sociais, econômicas e de tecnologia eram também moldados por essas redes que construíam. Isso envolvia, entre outras coisas, a contestação de uma ideia de neutralidade científica (KIEN, 2009). Posteriormente, foi em um trabalho ao lado de Latour (CALLON; LATTOUR, 1981) que essa ideia evolui para a negação de todo o dualismo. Os autores afirmavam que o dualismo existe apenas nas teorias sociais, não no mundo real. 
Artigo | Breve estudo sobre o materialismo e a Teoria do Ator-Rede com foco em sua corrente novo materialista (ALMEIDA, lan Coelho de Souza)

A ANT pode se aproximar da teoria da complexidade, por exemplo, como pode ser observado na obra de Bousquet e Curtis (2011). Segundo os autores a teoria da complexidade não deve ser considerada um corpo teórico unificado, mas "um conjunto de ferramentas teóricas e conceituais" (Ibidem, p.45, apud WALBY, 2007) ${ }^{20}$. O foco desse conjunto de ferramentas, que tiveram origem nas ciências naturais, seria a superação do método reducionista que buscava apenas a compreensão de elementos discretos que atuavam uns sobre os outros em sistemas fechados. Sendo assim, um sistemas não seria mais compreendido apenas por suas partes constituintes. No âmbito das ciências sociais, teoria da complexidade seria utilizada na análise de sistemas não-lineares de relacionamento. O que os autores chamam de "complexidade generalizada" seria a versão dessa teoria que mais teria preocupações próximas à ANT, continuam Bousquet e Curtis, como a emergência das relações e a sensibilidade às condições iniciais, tendo em vista, no entanto, compreender os fenômenos dentro de um sistema, ainda que um sistema aberto ${ }^{21}$.

Como já colocado, a Teoria do Ator-Rede à qual nos dedicaremos é a baseada em uma semiótica-materialista. Sendo a semiótica o estudo dos símbolos, o que a ANT coloca é ampliação para um movimento que vai dos símbolos para as coisas e de volta, o que também pode ser chamado de Semiótica das Máquinas (onde as máquinas são conjuntos de actants $^{22}$ humanos e não humanos) (Arkrich; Latour, 1992).

Law e Mol (1995) explicam a questão da Semiótica Materialista afirmando que a matéria ("objetos, entidades, atores, processos...") não existe em si mesma, mas é uma constituição das redes das quais fazem parte. "[M]atérias são construídas interativamente; fora de suas interações eles não têm existência, não têm realidade" (Ibidem, p.277, tradução própria). Sendo assim, a matéria, como explicado anteriormente, não é mais entendida enquanto algo inerte à espera da interação com o ser racional, o ser dotado de vitalidade. Tudo interage enquanto matéria, em sentido

\footnotetext{
20 Walby, Sylvia Complexity theory, systems theory, and multiple intersecting social inequalities, Philosophy of the Social Sciences, v. 37, 449-470, 2007.

${ }^{21}$ Cilliers (1998) a presenta a proximidade entre a teoria da complexidade a crítica pós -es truturalista.

22 Actants, por sua vez deve ser entendido como: "Whatever acts or shifts actions, action itself being defined by a list of performances through trials; from these performances are deduced a set of competences with which the actant is endowed; the fusion point of a metal is a trial through which the strength of an alloy is defined; the bankruptcy of a company is a trial through which the fa ithfulness of an ally may be defined; an actor is an actant endowed with a character (usually anthropomorphic)" (Arkrich; Latour, 1992, p. 259).
} 
Artigo | Breve estudo sobre o materialismo e a Teoria do Ator-Rede com foco em sua corrente novo materialista (ALMEIDA, lan Coelho de Souza)

amplo, e só têm existência enquanto interage. É esse materialismo que distinguirá a ANT da Semiótica Interpretativa do Construtivismo Social ${ }^{23}$.

"Tudo considerado enquanto matéria" é uma maneira de representar o nãohumanismo da ANT. Nela, humanos e não-humanos interagem em redes onde não existem hierarquias de importâncias. Para a teoria, laços que incluam não-humanos são aquilo que os sociólogos sempre buscaram como o que faltava na sociologia, um espaço que tentavam preencher com leis morais às quais estamos todos sujeitos (Latour, 1992, p.227). Levar em consideração nossa relação com esses não-humanos nos leva a modificar sensivelmente nosso entendimento, como pode ser visto em um exemplo dado por Latour: Uma simples porta, tecnologia inventada para dar acesso a espaços fechados, sem torna-los espaços novamente abertos (suscetível à entrada de ar frio, ou quente, ou animais indesejados, ou poeira e etc.), como seria no caso de um buraco em uma parede, requer uma série de outros entendimentos. A instalação da porta (máquina, tecnologia), por exemplo, só é eficaz enquanto todos os seres humanos que realizarão interações com ela entendem seu papel e são disciplinados o suficiente para mantê-la fechada após passarem. Essa necessidade pode dar surgimento a outra relação, a contratação de um porteiro, que seria responsável pela correta utilização do artefato, e trocaria o treinamento dos demais agentes pelo de apenas um, no entanto substituindo um esforço inicial de apenas se instalar uma porta com maçaneta no início do período, pela necessidade de um esforço constante do porteiro (não só constante, como também não-infalível) (Ibidem, 230-1). Sendo assim, a porta pode funcionar a partir do momento em que a maçaneta foi instalada, ou sempre que o porteiros estiver a postos. "Uma profunda modificação temporal ocorre quando se recorre a agentes não-humanos; o tempo é dobrado [folded]." (Ibidem, p.231, tradução própria)

Essa substituição, a de um humano fazendo o trabalho de um não-humano, pode ocorrer de modo inverso, principalmente se pensarmos em questões mais tecnológicas. Uma porta automática é um não-humano realizando o trabalho de um humano, o porteiro, que realiza um trabalho de um não-humano, a maçaneta. A substituição de um não-humano por um humano, explicitada acima, é a tentativa de não

\footnotetext{
${ }^{23}$ Schlottmann, Graefe e Korf (2010) é um interessante trabalho para entender as diferenças entre as duas semióticas. Para os autores, enquanto a materialista (ANT) busca descrever como relações são formadas de modo a contar suas estórias e nelas interferir, a interpretativa (Construtivismo Social) entende os significados que os sujeitos dão às práticas, objetos e etc.
} 
Artigo | Breve estudo sobre o materialismo e a Teoria do Ator-Rede com foco em sua corrente novo materialista (ALMEIDA, lan Coelho de Souza)

necessitar que toda a rede que interage com a porta seja responsável por garantir seu pleno funcionamento, relegando isso para apenas um ator da rede, o porteiro. Mas agora essa função é delegada novamente a um não-humano, o mecanismo de automação da porta. Não obstante, a porta automática irá impor aos atores humanos o saber de como se relacionar corretamente com ela, ou todos acabarão com seus narizes sangrando (Ibidem,p.232). Isso, o comportamento imposto por não-humanos a humanos, Latour chamará de prescription.

E não é aqui que terminam as novidades trazidas por esse novo não-humano que adentra à rede. Assimcomo o porteiro do qual é substituto, que pode, por exemplo, faltar um dia de trabalho, ou entrar em greve, os mecanismos de automação podem não funcionar corretamente. Partindo disso Latour pensa na maneira como usualmente pode-se dirigir a essa situação. No caso dele, utiliza a expressão "a porta automática está em greve", para exemplificar o modo como utilizamos expressões que se aplicam, de modo literal, apenas a humanos para descrever uma situação que envolve um nãohumano. Essa questão é interessante por deixar clara a distinção de abordagem de outras teorias, como a do construtivismo social, para a da ANT. Os primeiros tratam isso como uma projeção do comportamento humano para o não-humano, uma espécie de violação de barreiras naturais, um antropomorfismo, no entanto, para a ANT o antropomorfismo já havia sido iniciado há muito, dado que sua função é a de um agente humano ${ }^{24}$. $\mathrm{O}$ antropomorfismo não está apenas no entendimento do humano sobre o objeto, na ideia que o primeiro faz sobre o segundo, pois isso cai não só em um dualismo, mas também nega o materialismo. Na Teoria do Ator-Rede some a diferença entre humanos e não-humanos, que são entendidos apenas como atores de uma rede.

Apesar de parecer que tentamos aqui circunscrever a Teoria do Ator-Rede a um conceito bem definido, essa é uma tarefa ingrata, e considerada não correta ${ }^{25}$, segundo seus defensores. ANT não deve ser entendida enquanto teoria (Law, 2009; Mol, 2010).

\footnotetext{
24 'The groom is indeed anthropomorphic, in three senses: first, it has been made by humans; second, it substitutes for the actions of people and is a delegate that permanently occupies the position of a human; and third, it shapes human action by prescribing back what sort of people should pass through the door" (Latour, 1992, p.235). Com isso, não há sentido, para a ANT, em nega-lo qualquer propriedade que seja entendida como uma exclusividade do humano.

25 "Since 'ANT' has become an academic brand name, many authors start their articles with the promise that they will "use actor-network theory". Let me disappoint them: this cannot be done. It is impossible to "use ANT" as if it were a microscope. 'ANT' does not offer a consistent perspective." (Mol, 2010, p.261).
} 
Artigo | Breve estudo sobre o materialismo e a Teoria do Ator-Rede com foco em sua corrente novo materialista (ALMEIDA, lan Coelho de Souza)

Jonh Law afirma que ela nada mais é do que uma série de ferramentas, sensibilidades e métodos de análise da semiótica materialista, utilizados para descrever como relações são ou não agregadas - assembled - (o que a difere das teorias, que tem a intenção de explicar algo) através de estudos de caso. Por esse motivo, explicar o que é o materialismo semiótico, como tentamos fazer, é mais eficaz do que tentar explicar o que é a ANT, mesmo que exista outras correntes da ANT que apresentem diferenças. Avançando sobre o mesmo argumento, de que ANT não é uma teoria, Annemarie Mol, aponta como essa não busca explicar de onde vêm as ações dos atores, mas em que elas resultam, não em entendimento de objetivo/fim, mas de qualquer tipo de efeito. Ela lida com mudanças, que são captadas em cada um dos estudos de casos. Por esse motivo não pode se basear em uma série de pressupostos rígidos: "Portanto, toda a vez que um novo caso é considerado são sugeridas novas lições a respeito de o que um 'ator' deva ser" (Mol, 2010, p.257, tradução própria). Esses atores adquirem significado enquanto se relacionam com outros atores concretamente, na realidade, no material (diferentemente de outras semióticas, que focam em relações imateriais, da linguagem), formando suas redes que os permitem "atuar". É esse tipo de questão à qual nos referimos quando dizemos que a ANT dispões de ferramentas da Semiótica Materialista. O que a ANT pode oferecer a um autor, então, é um repertório contendo "termos sensíveis", formas de realizar perguntas e de revirar questões (Ibidem, p.261). Por fim, para Mol, ANT só pode ser considerada uma teoria caso modifique-se o significado de "teoria", assim como se faz com tudo o mais analisado pelas ferramentas da ANT.

Mesmo não se entendendo enquanto teoria, a ANT foi criticada enquanto uma, e influenciou autores diversas outras. Na literatura que conecta essas teorias (ou a teoria e a não-teoria) estão desde aqueles aproximam a ANT a diferentes abordagens marxistas, como é o caso de Söderberg e Netzén (2010), passando por aqueles que veem uma possibilidade de complementariedade (Gareau, 2005) ou proximidade (Van Loon, 2019), e desaguando em alegações de que Marx poderia ser visto como um teórico da ANT por tratar o processo de "comodificação" como uma espécie de relação ator-rede dialética (White, 2013). No geral, esses autores, antes de traçar as ligações entre Marx e ANT, ou criticar a última, apontam para como os autores da ANT comumente apresentam de maneira equivocada as ideias do filósofo alemão, ou resumem em uma 
Artigo | Breve estudo sobre o materialismo e a Teoria do Ator-Rede com foco em sua corrente novo materialista (ALMEIDA, lan Coelho de Souza)

descrição caricatura restrita das correntes do Marxismo para despois desmerece-las conjuntamente (dentre os estudiosos que utilizam o ferramental da ANT, Bruno Latour é o mais apontado a realizar esse tipo de equívoco). No entanto, esse apontamento é uma via de mão dupla, já que não é raro encontrar definições de ANT como estritamente pós-moderna, construcionista ou outras simplificações errôneas. Nossa intenção é fazer uma crítica dentro daquilo que os próprios autores da ANT entendem da teoria.

Mas o que as críticas dessas teorias têm em comum é a desatenção para um aspecto fundamental que expusemos durante esse trabalho: apesar de materialistas, 0 Materialismo Histórico e a Semiótica Materialista têm entendimentos diferentes sobre o que significa ser materialista. Sendo assim, tentar observar equivalências, aproximar conclusões, ou sugerir complementariedades, é um trabalho nem sempre efetivo. Isso não significa que críticas marxistas não possam ser feitas e não estejam corretas. Uma opção, por exemplo, a partir da análise da porta que apresentamos acima, seria argumentar que mesmo tentando evitar a dicotomia humano/não-humano Latour estaria mascarando que, na realidade, a matéria que entraria na rede de modo não hierárquico, só o faz se antes for objeto do trabalho humano (hierárquico, dual e etc.), ou caso então realize ação sobre algo que o sofreu a modificação ou mesmo sobre aquilo que contém a força de trabalho (o homem). Veja o caso de uma pedra. Uma pedra que cai em um lago por ação do vento não está realizando trabalho que antes era de um ser humano, ou qualquer outro tipo de analogia. O importante é que não há antropomorfismo, sendo assim, pela própria definição de Akrich e Latour (1992), não há ator, portanto não há rede. No entanto, se a pedra cai de uma colina (por um terremoto, por exemplo) e destrói uma casa, que aqui nós enxergamos como a destruição do trabalho humano morto cristalizado na casa, existe o antropomorfismo, existe o ator e existe a rede (apesar de efêmera). O que estamos argumentando é que, apesar da ANT se dizer não hierárquica, ela depende inicialmente da ação humana sobre o objeto inanimado, depende desses entendimentos de relações duais, para iniciar sua Análise. Do modo que nós vemos, continua válida a ideia de Marx de que a história do homem tem seu início no trabalho.

Para além do que colocamos, a ideia de que a vitalidade da matéria por meio do antropomorfismo ter como pressuposto, em algum momento, o trabalho, há ainda de se considerar o que coloca Žižek (2014, p.9): "Se um cuidadoso caminho de 
Artigo | Breve estudo sobre o materialismo e a Teoria do Ator-Rede com foco em sua corrente novo materialista (ALMEIDA, lan Coelho de Souza)

antropomorfismo pode ajudar a revelar a vitalidade dos bens materiais, não está claro se essa vitalidade é um resultado de nossa percepção sendo animista ou de um poder vital subjetivo". Sendo assim, a ideia de Novo Materialismo ainda encontrará diversas barreiras antes de superar suas caracterizações de "animismo terrestre" ou "ingenuidade pré-moderna", como coloca o próprio Žižek.

\section{Conclusão}

A intenção inicial desse artigo foi a de comparar o entendimento de materialismo presente na teoria do Materialismo Histórico de Marx, sem entrar nas comparações dos desenvolvimentos posteriores desse método ao longo do século XX, e de uma versão da Teoria do Ator-Rede, da qual Bruno Latour é o nome mais proeminente.

Primeiramente mostramos como Marx desenvolve o materialismo incipiente de Feuerbach, em sua tentativa inicial de se afastar de Hegel, e como a dialética do último é questão a ser mantida como modo de não se cair no materialismo mecanicista e ingênuo trabalhado por alguns filósofos alemães no século XIX, que transportavam conceitos diretamente análises da física, como a de Demócrito - o que acaba por limitalos enquanto apenas uma crítica à espiritualidade. Outro ponto importante é como a Teoria do Ator-Rede, em sua proximidade com a Semiótica Materialista, se baseia em uma nova reformulação do que é o materialismo, o "Novo Materialismo". Aqui a matéria deixa de representar algo inerte, à espera da ação humana, ser dotado de vitalidade, de um ser racional sobre um irracional. Esse será um ponto crucial na intenção de findar com análises focadas em dualismos, sejam modernas ou pós-modernas.

Ademais, sugerimos que as críticas marxistas feitas à Teoria do Ator-Rede devem levar em consideração essa diferença entre seus materialismos, principalmente quando se sugere que ANT pode ser encontrada dentro do trabalho de Marx, ou quando se propõe complementariedade. Por fim, utilizar as próprias concepções divergentes sobre a matéria pode ser uma forma válida de se construir críticas, algo como aquilo que esboçamos brevemente ao fim da última sessão. 
Artigo | Breve estudo sobre o materialismo e a Teoria do Ator-Rede com foco em sua corrente novo materialista (ALMEIDA, lan Coelho de Souza)

\section{Bibliografia}

AKRICH, Madeleine; LATOUR, Bruno. A summary of a convenient vocabulary for the semiotics of human and nonhuman assemblies, In: Wieber Bijker and John Law (eds.), Shaping Technology/Building Society, Cambridge: MIT Press, 1992, pp.259-264.

BENNET, Jane. A Vitalist stopover on the way to a New Materialism. In: Diana Coole and Samantha Frost, New Materialism: Ontology, Agency, and Politics. Durham: Duke University Press, 2010, pp. 47-69.

BERNSTEIN, Howard R. Marxist Historiography and the Methodology of Research Programs. History and Theory, v.20, no 4, 1981, pp.424-449.

BERTRAND, Russel. Introduction: Materialism past and Present. In: Frederick Lange, The History of Materialism and criticism of its present importance. New York: Harcourt, Brace \& Company, Inc., 1925, pp. V-XIX.

BOUSQUET, Antonie; CURTIS, Simon. Beyond models and metaphors: complexity theory, systems thinking and international relations. Cambridge Review of International Affairs, v. 24, n. 1, 2011, pp.43-62.

BURAWOY, Michael. Marxism as Science: Historical Challenges and Theoretical Growth. American Sociological Review, v.55, 1990, pp.775-793.

CALLON, Michel; LATOUR Bruno. Unscrewing the Big Leviathan: How Actors Macrostructure Reality and How Sociologists Help Them to Do So. In: KNORR-CETINA, K.; CICOUREK, A. Advances in Social Theory and Methodology: Toward an Integration of Micro- and Macro-Sociologies,. Boston, MA: Routledge and Kegan Paul., 1981, pp. 277303.

CILLIERS, Paul. Complexity and postmodernism: understanding complex systems, London: Routledge, 1998,

COLEBROOK, Claire. Postmodernism is a humanism: Deleuze and equivocity. Women: A Cultural Review, v.15, no 3, 2004, pp.283-307.

COOLE, Diana. The Inertia of Matte and the Generativity of Flesh. In: Diana Coole and Samantha Frost, S. New Materialism: Ontology, Agency, and Politics. Durham: Duke University Press, 2010, pp. 92-115.

COOLE, Diana; FROST, Samantha. Introducing New Materialism. In: Diana Coole and Samantha Frost, New Materialism: Ontology, Agency, and Politics. Durham: Duke University Press, 2010, pp. 1-43.

DELEUZE, Gilles; GUATTARI, Félix. A Thousand Plateaus: Capitalism and Schizophrenia, Minneapolis: University of Minnesota Press, 1987.

DOLPHIJN, Rick; VAN DER TUIN, Iris. Pushing Dualism to an extreme: On the philosophical impetus of a New Materialism. Continental Philosophical Review, v. 44, 2011, pp. 383-400. 
Artigo | Breve estudo sobre o materialismo e a Teoria do Ator-Rede com foco em sua corrente novo materialista (ALMEIDA, lan Coelho de Souza)

EDWARDS, Jason. The materialism of Historical Materialism. In: Diana Coole and Samantha Frost, New Materialism: Ontology, Agency, and Politics. Durham: Duke University Press, 2010, pp. 281-317.

ELDER-VASS, Dave. Disassembling Actor-Network Theory. Philosophy of the Social Sciences, v. 44, n. 1, 2015, pp. 100-121.

ENGELS, Friedrich. Ludwig Feuerbach e o fim da Filosofia Clássica Alemã. In: Karl Marx e Friedrich Engels, A Ideologia Alemã: Feuerbach - A Contraposição entre as Cosmovisões Materialistas e Idealista. São Paulo: Martin Claret, 2006, pp.121-139.

FENWICK, T.; EDWARDS, R. (2011). Introduction: Reclaiming and Renewing Actor Network Theory for Educational Research. Educational Philosophy and Theory, 43(sup1), pp. 1-14.

GAREAU, Brian. We have Never Been Human: Agential Nature, ANT, and Marxist Political Ecology. Capitalism Nature Socialism, v.16, no 4, 2005, pp.127-140.

GONTIJO, Erik H. Natureza, sociedade e atividade sensível na formação do pensamento marxiano. 2008. Dissertação (Mestrado em Filosofia) - Programa de PósGraduação em Filosofia da Universidade Federal de Minas Gerais.

GREGORY, Frederick. Scientific versus Dialectical Materialism: A Clash of ideologies in the Nineteenth-Century German Radicalism. ISIS, v.68, no 242, 1977, p.206-223.

HOOK, Sidney. The Philosophy of Dialectical Materialism I. The Journal of Philosophy, v. XXV, no 5, 1928, pp.113-124.

KIEN, Grant. Actor-network theory: Translation as material culture. In VANNINI, P. Material culture and technology in everyday life: Ethnographic approaches, 2009, pp. 27-44.

LATOUR, Bruno. Where are the missing masses? The Sociology of a few munda ne Artifacts. In BIJKER, W; LAW, J (eds) Shaping Technology/Building Society, Cambridge: MIT Press, 1992, pp.225-258.

On Recalling ANT. The Sociological Review. v.47, no 1, 1999, pp.15-

25.

LAW, John. Actor Network Theory and Material Semiotics. In Bryan S. Turner (ed.). The New Blackwell companion for Social Theory, 2009, pp.141-158.

LAW, John; MOL, Annemarie. Notes on materiality and sociality. The Sociological Review, v.43, no 2, 1995, pp.274-294.

LANGE, Frederick A. The History of Materialism and criticism of its present importance. First Book, 3 Volumes. 1a Edição [1865] New York: Harcourt, Brace \& Company, Inc., 1925.

LEFEBVRE, Henri. Lógica Formal Lógica Dialética. São Paulo: Civilização Brasileira, 1995.

VAN LOON, Joost. Historical Materialism and Actor-Network-Theory. In: KISSMANN, U. T.; VAN LOON, J. Discussing New Materialism. Springer VS, Wiesbaden, 2019. p. 39-65. 
Artigo | Breve estudo sobre o materialismo e a Teoria do Ator-Rede com foco em sua corrente novo materialista (ALMEIDA, lan Coelho de Souza)

MARX, Karl. Teses ad Feuerbach In: Karl Marx e Friedrich Engels, A Ideologia Alemã: Feuerbach - A Contraposição entre as Cosmovisões Materialistas e Idealista. São Paulo: Martin Claret, 2006, pp.117-120.

. Manuscritos econômicos-filosóficos. São Paulo: Boitempo, 2010. . Contribuição à Crítica da Economia Política. 1a Edição [1859] São

Paulo: Editora WMF Martins Fontes, 2011.

MARX, Karl; ENGELS, Friedrich. The German Ideology. New York: Prometheus Books, 1998.

MOL, Annemarie. Actor-Network Theory: Sensitive Terms and Enduring Tensions. Kölner Zeitschrift für Soziologie und Sozialpsychologie, v.50, 2010, pp.253-269.

OLIVEIRA, Renato A. A concepção de trabalho na filosofia do jovem Marx e suas implicações antropológicas. Kínesis, Marília, v. II, no 03, pp. 72-88.

PLEASANTS, Nigel. The Post-Positivist dispute in Social Studies of Science and its bearing on Social Theory. Theory, Culture \& Society, v. 14, no 3, 1997, pp.143-156.

REYDESON, Deyve. Ludwig Feuerbach e o jovem Marx: a religião e o materialis mo antropológico dialético. Argumentos, v.3, no 5, 2011, pp.7-13.

SAMPAIO, Benedicto A.; FREDERICO, Celso. Dialética e Materialismo: Marx entre Hegel e Feuerbach. Rio de Janeiro: Editora UFRJ, 2009.

SCOTT, Joan W. Only paradoxes to offer: French feminists and the rights of man. Cambridge: Harvard University Press, 1996.

SCHLOTTMANN, Antje; GRAEFE, Oliver; KORF, Benedikt. Things that matter: A dialogue on interpretative and material semiotics in geography. Geographische Zeitschrift, v.98, no 4, 2010, pp.226-236.

SERRES, Michel; LATOUR, Bruno. Third Conversation: Demonstration and Interpretation In Michel Serres e Bruno Latour, Conversations on Science, Culture, and Time, Ann Arbor: University of Michigan Press, 1995, pp. 77-123.

SILVERIA JÚNIOR, Adilson. O nexo necessário e vital: Ideologia e História em Marx. Temporalis, ano13, no 26, 2013, pp.37-54.

SÖDEBERG, Johan; NETZÉN, Adam. When all that is theory melts into (hot) air: Contrasts and parallels between actor network theory, autonomist Marxism, and open Marxism. Ephemera, v.10, no 2, 2010, pp.95-118.

SORREL, Tom. Seventeenth-century materialism: Gassendi and Hobbes. In: George HR Parkinson (ed.) Routledge History of Philosophy, Volume IV: The Renaissance and the Seventeenth-century Rationalism, 2005, pp.219-252.

THERBORN, Gorän. Science, Class and Society: On the formation of Sociology and Historical Materialism. London: Lowe and Brydone, 1976. From Marxism to Post-Marxism? Londres: Verso Books, 2008.

VAISMAN, Ester. A ideologia e sua determinação ontológica. Verinotio, anoVI, no 12, 2010, pp. 40-64.

VAN DER TUIN, Iris; DOLPHIJN, Rick. The Transversality of New Materialism. Women: a cultural review, v. 21, n.2, 2010, pp. 153-171. 
WARTOFSKY, Marx. Foreword. In GREGORY, Frederick. Scientific Materialism in Nineteenth Century Germany. Boston: D. Reidel Publishing Company, 1977.

WHITE, Hylton. Materiality, Form, and Context: Marx contra Latour. Victorian Studies, v.55, no 4, 2013, pp. 667-682.

WILSON, Catherine. Motion, Sensation, and the Infinite: The Lasting Impressions of Hobbes on Leibniz. British Journal for the History of Philosophy. v.5, no 2, 1997, pp. 339-351.

ŽlŽEK, Slavoj. Absolute Recoil: towards a new foundation of dialectical materialism. Londres: Verso Books, 2014. 